\title{
High-Performance Lignin-containing Polyurethane Elastomers with Dynamic Covalent Polymer Networks
}

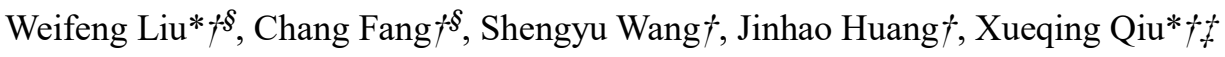

$广$ School of Chemistry and Chemical Engineering, Guangdong Engineering Research Center for Green Fine Chemicals, South China University of Technology, Wushan Road 381, Guangzhou, Guangdong, 510640, China

$\mp$ State Key Laboratory of Pulp and Paper Engineering, South China University of Technology, Wushan Road 381, Guangzhou, Guangdong, 510640, China

$\S$ These authors contributed equally.

*Corresponding authors

E-mail: weifengliu@scut.edu.cn (W. Liu); cexqqiu@scut.edu.cn (X. Qiu)

Tel.: +86 020-87114722

\section{Characterizations}

The hydroxyl amount of lignin was calculated from ${ }^{31} \mathrm{P}$ NMR spectra via formula FS1.

$$
Y=\frac{\frac{\mathrm{c} \times 100}{100.16} \times \frac{A_{1}}{A_{2}}}{m}
$$

Where, $\mathrm{Y}$ — the hydroxyl content of lignin, $\mathrm{mmol} / \mathrm{g}$;

$\mathrm{c}$ _ the concentration of internal standard, $\mathrm{mg} / \mathrm{mL}$;

100 - the additive amount of internal standard, $\mathrm{mL}$;

100.16 — the molar mass of internal standard, $\mathrm{g} / \mathrm{mol}$;

A1_ - the internal area of signal of hydroxyl groups in internal standard;

A2 _ the internal area of the signal of hydroxyl groups in lignin;

$\mathrm{m}$ — the mass of lignin, $\mathrm{mg}$ 
The Young's modulus and elastic recovery were calculated from formula FS2 and FS3.

$$
W=\int_{\varepsilon=0}^{\varepsilon=\varepsilon_{\max }} \sigma d \varepsilon
$$

Where, $\sigma$ - tensile stress, $\mathrm{MPa}$;

$\varepsilon-$ tensile strain, \%.

$$
\text { elastic recovery }=\frac{l_{\max }-l_{\text {recovery }}}{l_{\max }-l_{0}} \times 100 \%
$$

Where, $l_{0}$ the initial length of spline, $\mathrm{cm}$;

$l_{\max }$ the maximum length of spline when stretching, $\mathrm{cm}$;

$l_{\text {recovery }}$ the length of broken spline after recovering $2 \mathrm{~h}$ at room temperature, $\mathrm{cm}$.

The solvent extraction method was used to measure the gel rate $\left(G_{f}\right)$ of lignin-containing polyurethane elastomers. Approximate $0.5 \mathrm{~g}$ sample $\left(m_{0}\right)$ was weighted and put into $20 \mathrm{~mL}$ DMAC, and the immersion experiment was conducted at room temperature for 72 hours to dissolve non-crosslinking structures and reach swelling equilibrium, after which filter papers were used to remove superficial solvent of sample and the mass of sample at this point was written down as $m_{1}$. The insoluble part was separated from the solution and vacuum dried at $70{ }^{\circ} \mathrm{C}$ for $24 \mathrm{~h}$ and its mass was taken down as $m_{2}$. The $\mathrm{G}_{\mathrm{f}}$ of the sample was calculated via formula FS4.

$$
G_{\mathrm{f}}=\frac{m_{2}}{m_{0}} \times 100 \%
$$

In polymer industry, SAXS was used to calculated the thickness $\left(l_{c}\right)$ and long period of the crystalline layer $(L)$ in semi-crystalline polymer, as shown in Figure S1. ${ }^{[1-2]}$ The two-dimension SAXS figures was transformed to one-dimension curves via Fit2D software. The thickness of amorphous area $\left(l_{a}\right)$ could be calculated via formula FS5.

$$
l_{a}=L-l_{c}
$$

Where, $L-$ long period of crystalline layer $l_{c} \_$the crystallization thickness. 


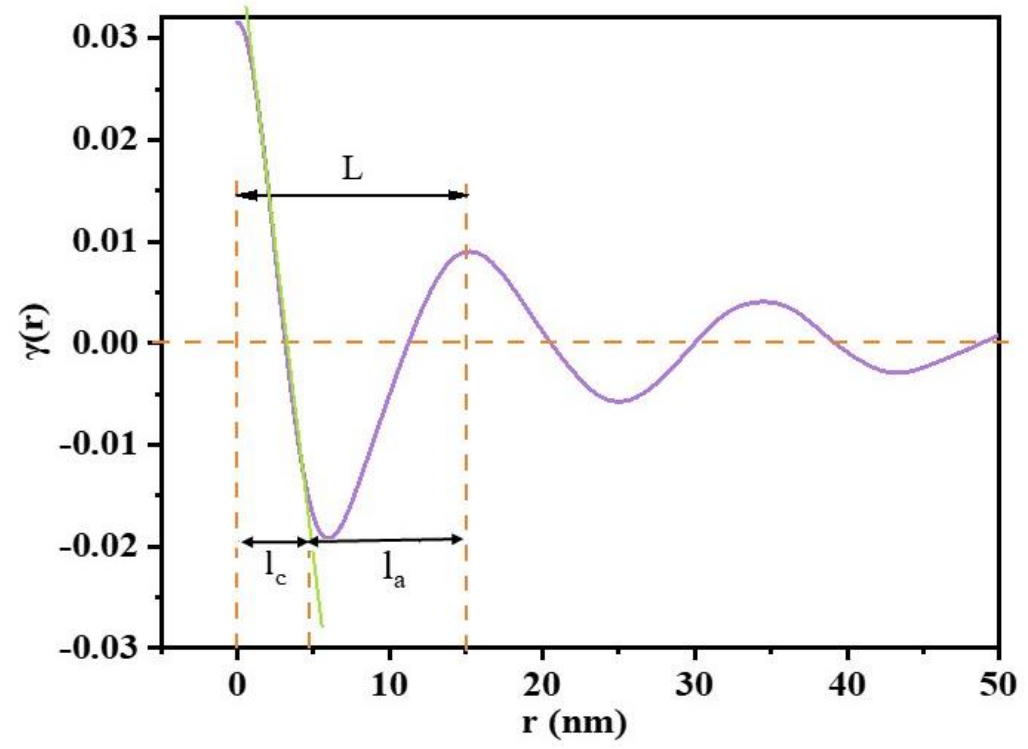

Figure S1. 1D correlation function curve. 


\section{Results and discussion}

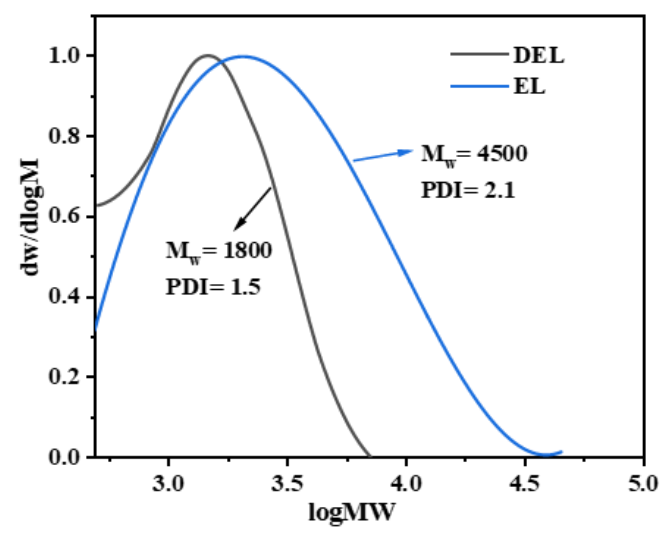

(a)

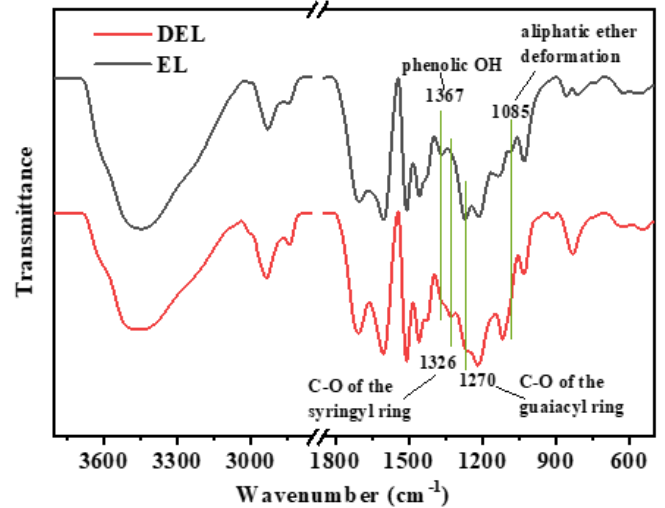

(b)

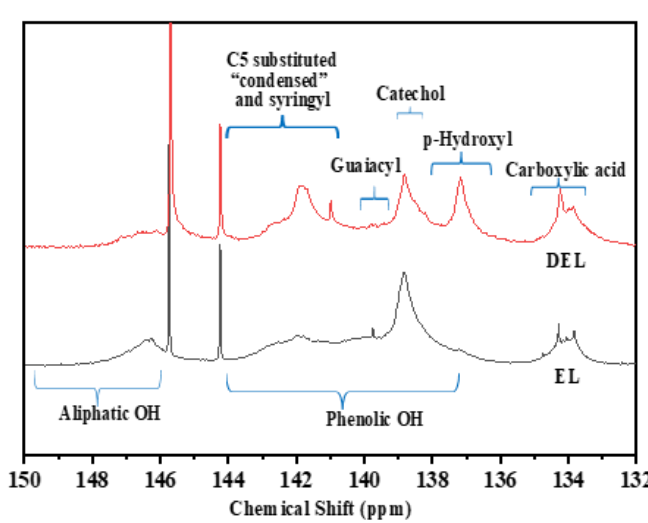

(c)

Figure S2. (a) GPC curves of EL and DEL; (b) FT-IR spectra of EL and DEL; (c) ${ }^{31} \mathrm{P}$ NMR spectra of EL and DEL.

The structure of El and DEL was characterized by FT-IR spectra, as shown in Figure S2b. There was no apparent difference between EL and DEL, indicating that partially depolymerization in relatively mild condition didn't break the basic aromatic skeleton structure of lignin. The absorption peak at $1085 \mathrm{~cm}^{-1}$ attributing to aliphatic ether bonds weakened in the curve of DEL because of the breakage of aliphatic ether bonds at high temperature and pressure in alkaline condition. ${ }^{[3]}$ Compared with EL, DEL showed a significant decrease in the peak intensity at $1270 \mathrm{~cm}^{-1}$, which was assigned to the stretching vibration of $\mathrm{C}-\mathrm{O}$ in guaiacyl structures. Meanwhile, the peak at $1326 \mathrm{~cm}^{-1}$ attributing to the stretching vibration of $\mathrm{C}-\mathrm{O}$ in syringyl structures 
appeared in the curve of DEL, indicating that the depolymerization of EL decreased the content of guaiacyl structures and increased the content of syringyl structures. ${ }^{[4,5]}$ Remarkably, the intensity at $1367 \mathrm{~cm}^{-1}$ increased in DEL, indicating that the depolymerization of EL produced more phenolic hydroxyl groups, which would be beneficial to increase the reactivity of DEL and construct more hydrogen bonds in polyurethane matrix. ${ }^{[6]}$

Table S1. Hydroxyl group contents of lignin calculated from ${ }^{31} \mathrm{P}$ NMR spectra

\begin{tabular}{llll}
\hline $\begin{array}{l}\text { Chemical shift } \\
(\mathrm{ppm})\end{array}$ & \multirow{2}{*}{ Assignment } & \multicolumn{2}{l}{ Lignin (mmol/g) } \\
\cline { 3 - 4 } & & $\mathrm{EL}$ & $\mathrm{DEL}$ \\
\hline $150.0-145.5$ & aliphatic hydroxyl group & 1.29 & 1.26 \\
$136.6-144.7$ & Overall phenolic hydroxyl group & 3.92 & 4.36 \\
& Phenolic hydroxyl group in C5-substituted, & 1.77 & 1.94 \\
$144.7-140.0$ & $\begin{array}{l} \\
\end{array}$ & syringyl and condensed structures & \\
$140.0-139.0$ & Phenolic group in guaiacyl structure & 0.32 & 0.46 \\
$139.0-138.2$ & Phenolic group in catechol structure & 1.49 & 0.85 \\
$138.2-137.3$ & Phenolic group in p-hydroxyl structure & 0.34 & 1.12 \\
$136.6-133.6$ & Carboxylic acid group & 0.75 & 1.09 \\
\hline
\end{tabular}

The total contents of hydroxyl groups in EL and DEL were evaluated by quantitative ${ }^{31} \mathrm{P}$ NMR spectra. The results were shown in Figure S2c and Table S1. The signals at $\delta 150.0-145.5$ and $\delta 144.7-136.6$ were assigned to the aliphatic and phenolic hydroxyl groups, respectively. Consistent with the FT-IR results, the content of phenolic hydroxyl groups increased from $3.92 \mathrm{mmol} / \mathrm{g}$ in EL to $4.36 \mathrm{mmol} / \mathrm{g}$ in DEL, while the content of aliphatic hydroxyl groups did not vary too much after depolymerization. The total content of hydroxyl groups in EL and DEL were 5.21 $\mathrm{mmol} / \mathrm{g}$ and $5.62 \mathrm{mmol} / \mathrm{g}$, respectively. Besides, the phenolic hydroxyl groups in C5-substituted, syringyl, condensed, guaiacyl and p-hydroxyl structures significantly increased, indicating the breakage of phenol ether bonds in lignin after partial depolymerization. ${ }^{[7]}$ The content of carboxylic acid groups also increased due to the hydrolysis of ester groups under alkaline condition. 
Table S2. Gel fraction of polyurethane elastomers with different amounts of lignin.

\begin{tabular}{cc}
\hline Samples & Gel ratio (\%) \\
\hline Control & 58.0 \\
$5 \% \mathrm{DEL}$ & 62.7 \\
$10 \% \mathrm{DEL}$ & 92.0 \\
$10 \% \mathrm{EL}$ & 92.7 \\
$20 \% \mathrm{DEL}$ & 94.1 \\
$40 \% \mathrm{DEL}$ & 83.7 \\
$60 \% \mathrm{DEL}$ & 70.3 \\
\hline
\end{tabular}

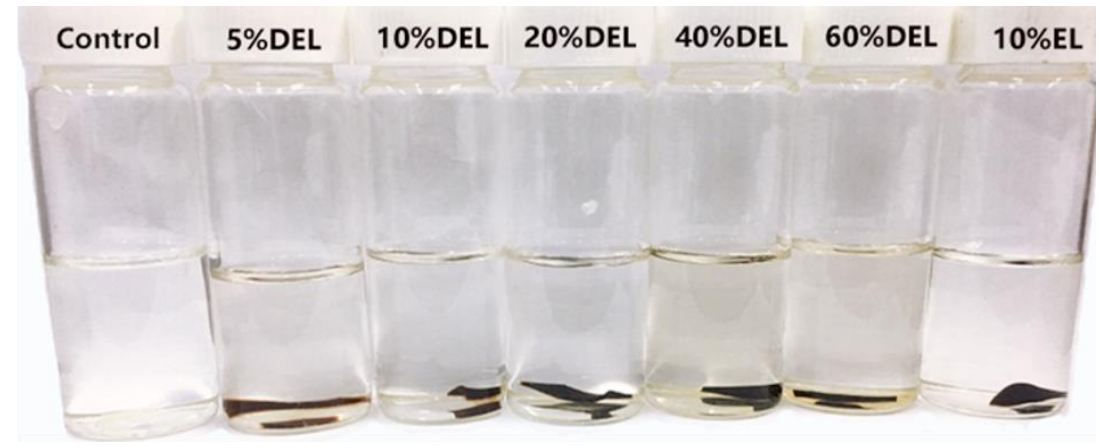

(a) Before swelling

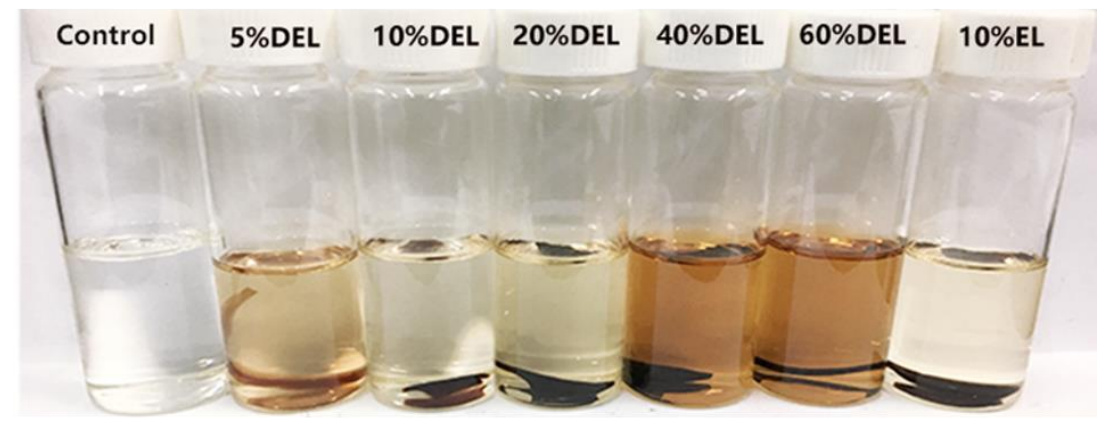

(b) After swelling

Figure S3. Swelling tests of polyurethane elastomers with different amounts of lignin 
Table S3. Mechanical properties of lignin-containing polyurethane elastomers

\begin{tabular}{cccccc}
\hline Samples & $\begin{array}{c}\text { Tensile } \\
\text { strength(MPa) }\end{array}$ & $\begin{array}{c}\text { Elongation at } \\
\text { break(\%) }\end{array}$ & $\begin{array}{c}\text { Young's } \\
\text { modulus(MPa) }\end{array}$ & $\begin{array}{c}\text { Tensile } \\
\left.\text { Toughness(MJ } / \mathrm{m}^{3}\right)\end{array}$ & $\begin{array}{c}\text { Elastic } \\
\text { recovery(\%) }\end{array}$ \\
\hline Control & 8.03 & 559 & 26.9 & 30.6 & $83 \%$ \\
$5 \% \mathrm{DEL}$ & 60.7 & 1310 & 7.5 & 263.6 & $96 \%$ \\
$10 \% \mathrm{DEL}$ & 57.8 & 1200 & 9.6 & 244.5 & $95 \%$ \\
$10 \% \mathrm{EL}$ & 28.3 & 955 & 9.3 & 115.2 & $94 \%$ \\
$20 \% \mathrm{DEL}$ & 39.3 & 961 & 23.8 & 162.2 & $90 \%$ \\
$40 \% \mathrm{DEL}$ & 24.1 & 707 & 110.0 & 110.7 & $85 \%$ \\
$60 \% \mathrm{DEL}$ & 8.23 & 244 & 31.0 & 15.9 & $84 \%$ \\
\hline
\end{tabular}

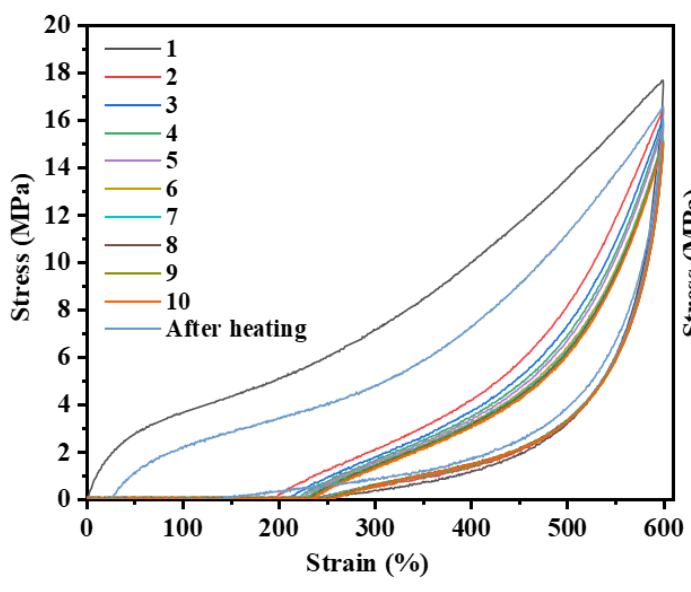

(a)

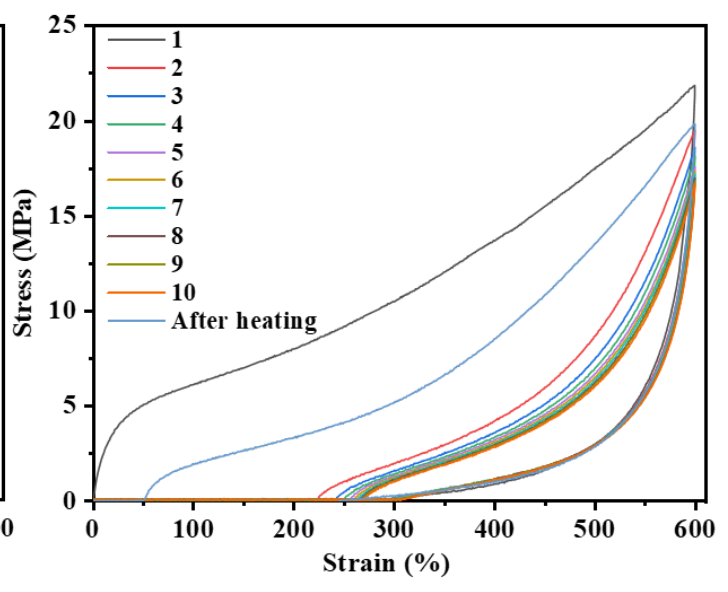

(b)

Figure S4. Tensile hysteresis curve of polyurethane elastomers with different amount of DEL at the fixed strain of $600 \%$ (a) $10 \% \mathrm{DEL}$ (b) $20 \% \mathrm{DEL}$ 


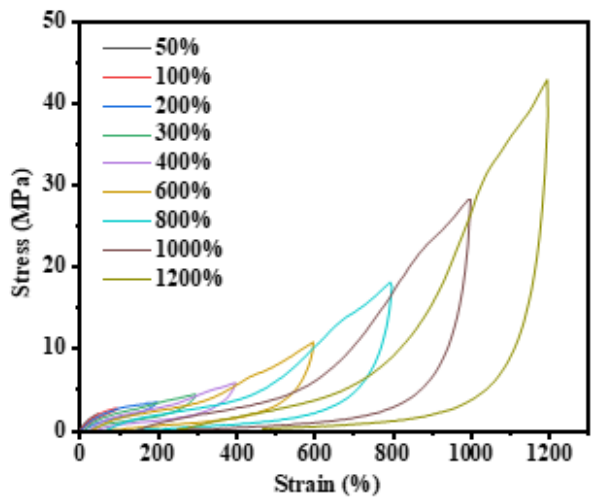

(a)

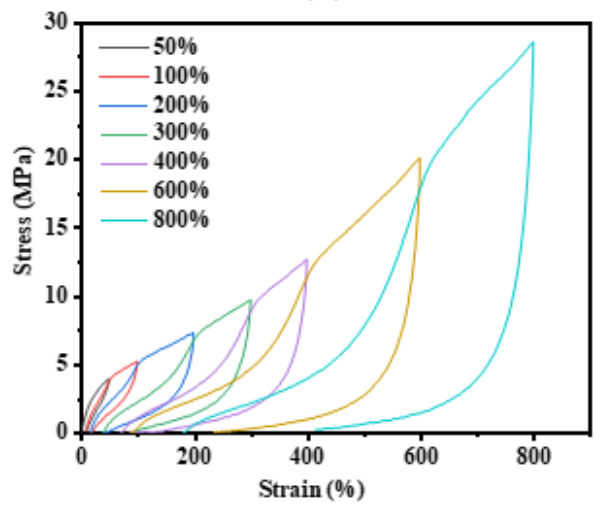

(c)

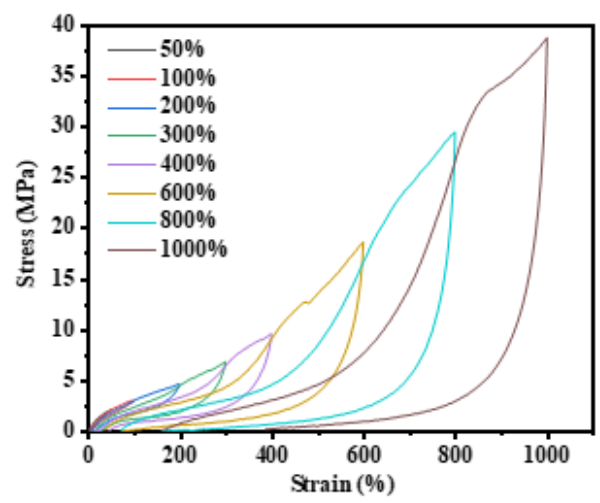

(b)

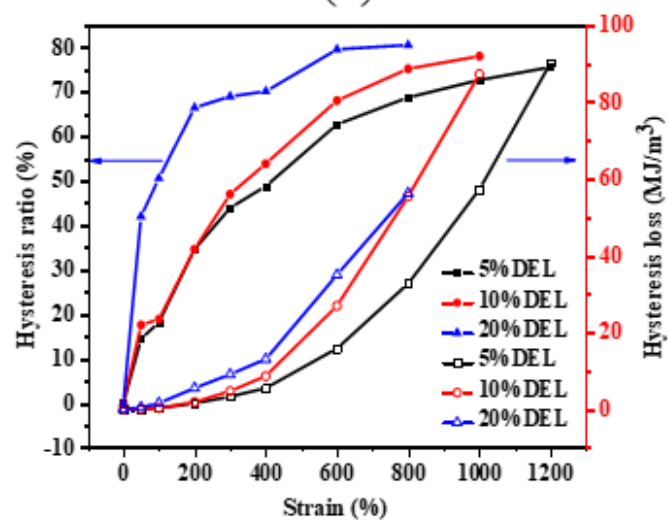

(d)

Figure S5. Variational hysteresis curves of polyurethane elastomers with different amount of DEL (a) $5 \% \mathrm{DEL}$ (b) $10 \% \mathrm{DEL}$ (c) $20 \% \mathrm{DEL}$; (d) Hysteresis loss and hysteresis loss ratio calculated by the hysteresis curves at various strains
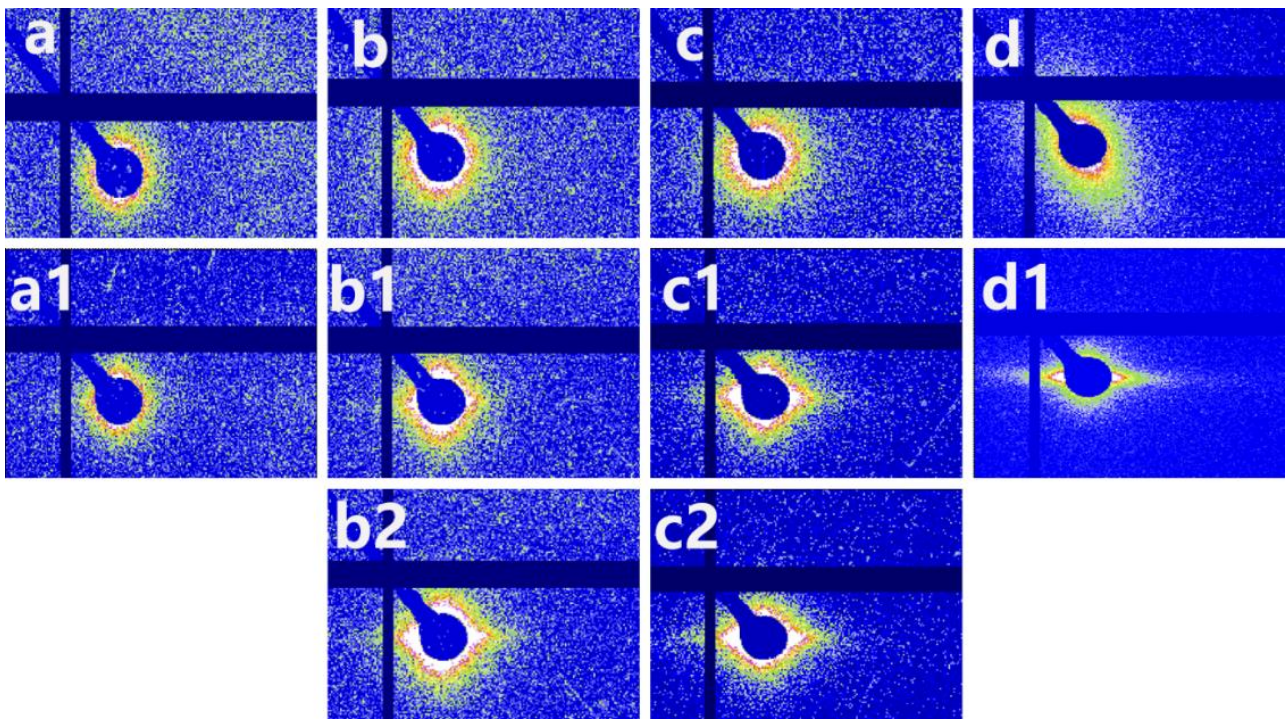

Figure S6. 2D SAXS scattering patterns of lignin-containing polyurethane elastomers: a, b, c, and $\mathrm{d}$ are scattering patterns of Control, $5 \% \mathrm{DEL}, 10 \% \mathrm{DEL}$, and $20 \%$ DEL at $0 \%$ strain, respectively; $\mathrm{a} 1, \mathrm{~b} 1, \mathrm{c} 1$ and $\mathrm{d} 1$ are the scattering patterns of the corresponding samples at $500 \%$ strain; b2 and c2 are the scattering patterns of the corresponding samples at 1000\% strain. 

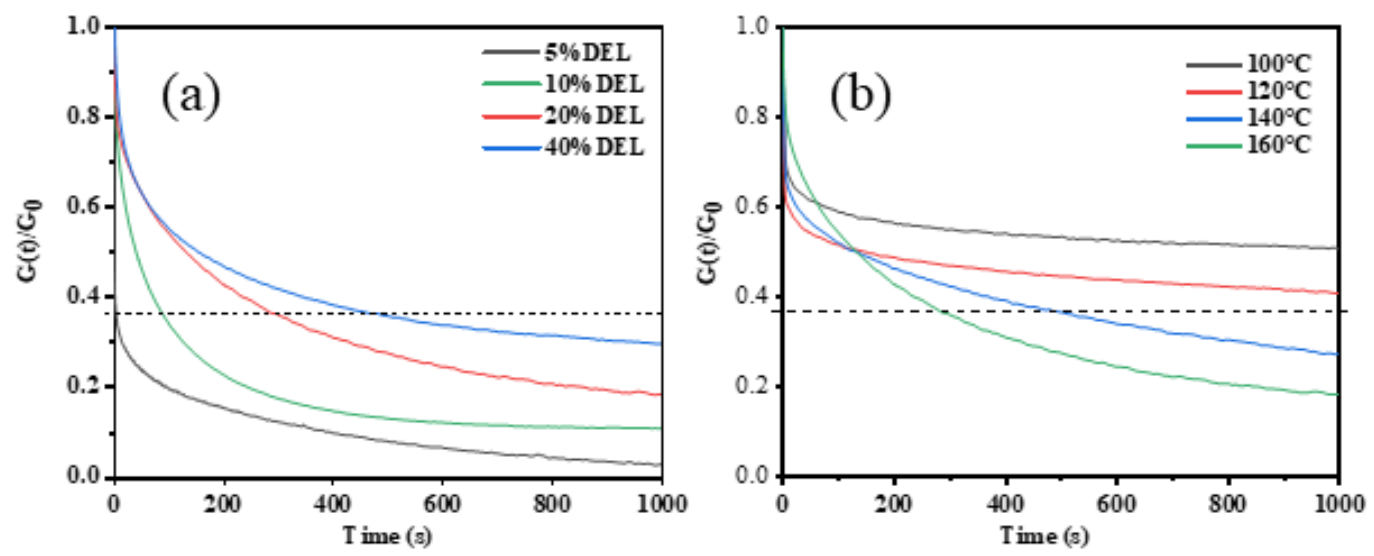

Figure S7 (a) Stress relaxation curves of polyurethane elastomers with different amount of DEL at $160{ }^{\circ} \mathrm{C}$; (b) Stress relaxation curves of $20 \mathrm{wt} \%$ DEL at different temperatures.

Table S4. Comparison of mechanical properties for lignin-based polyurethane elastomers after two times hot pressing

\begin{tabular}{|c|c|c|c|c|}
\hline \multicolumn{2}{|c|}{ Samples } & \multirow{2}{*}{$\begin{array}{c}\text { Pristine } \\
60.7\end{array}$} & \multirow{2}{*}{$\frac{\text { Re-molding }}{45.0}$} & \multirow{2}{*}{$\begin{array}{c}\text { Retention ratio } \\
(\%) \\
74.1\end{array}$} \\
\hline & $5 \%$ DEL & & & \\
\hline 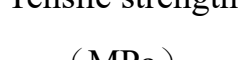 & $10 \% \mathrm{DEL}$ & 57.8 & 37.7 & 65.2 \\
\hline & $20 \%$ DEL & 39.3 & 28.5 & 72.5 \\
\hline \multirow{3}{*}{$\begin{array}{l}\text { Elongation at } \\
\text { break }(\%)\end{array}$} & $5 \%$ DEL & 1310 & 1423 & 108.6 \\
\hline & $10 \% \mathrm{DEL}$ & 1200 & 1165 & 97.1 \\
\hline & $20 \%$ DEL & 961 & 836 & 87.0 \\
\hline \multirow{3}{*}{$\begin{array}{c}\text { Young's } \\
\text { modulus (MPa) }\end{array}$} & $5 \%$ DEL & 7.5 & 7.8 & 104.0 \\
\hline & $10 \% \mathrm{DEL}$ & 9.6 & 9.8 & 102.1 \\
\hline & $20 \%$ DEL & 23.8 & 20.5 & 86.1 \\
\hline
\end{tabular}




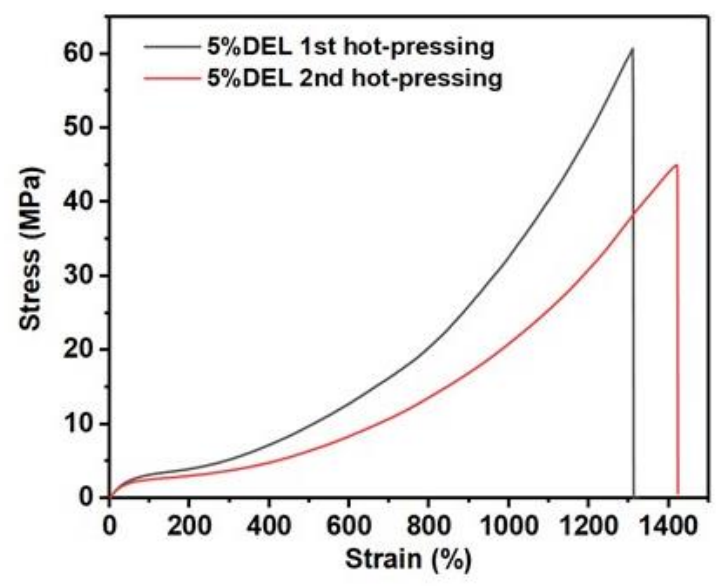

(a)

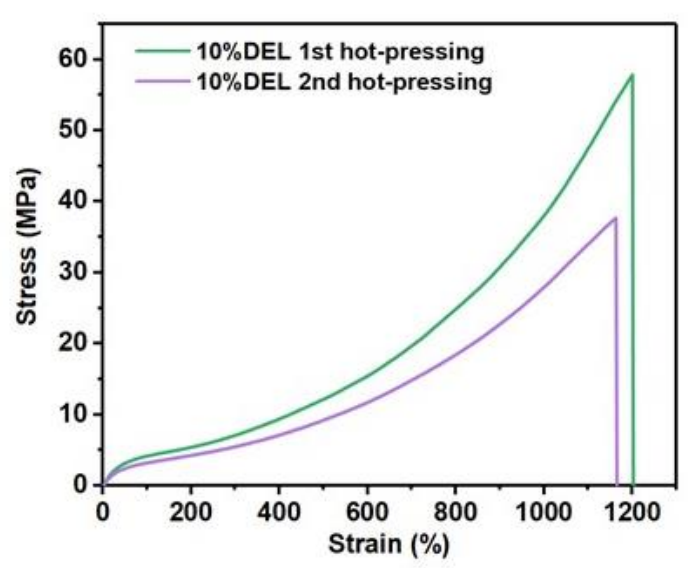

(b)

Figure S8. Stress-strain curves of polyurethane elastomers after the first and second hot pressing.

(a) $5 \% \mathrm{DEL}$ (b) $10 \% \mathrm{DEL}$. The hot-pressing time was $5 \mathrm{~min}$ and the pressing temperature was $160^{\circ} \mathrm{C}$ for both hot-processing.
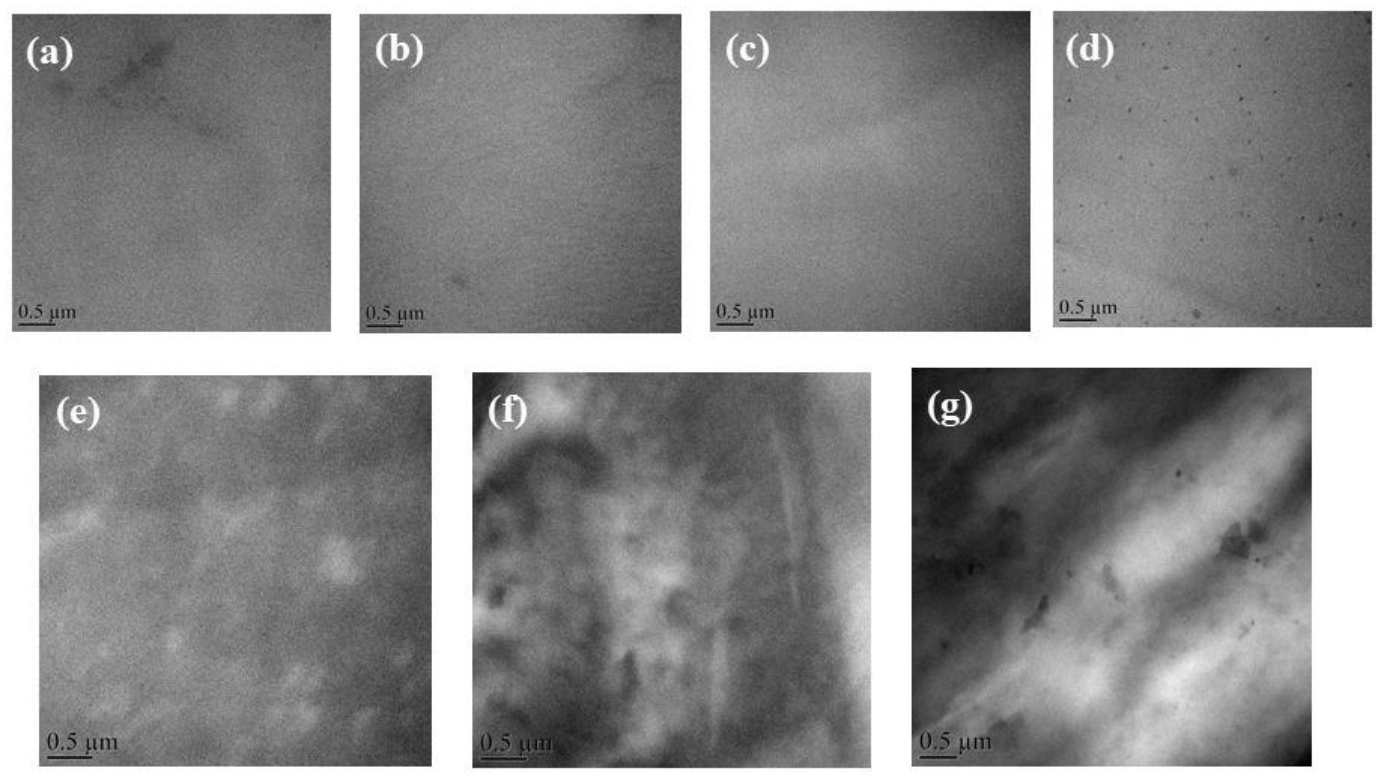

Figure S9. TEM images of polyurethane elastomers. (a): the control sample (b): 5\%DEL (c)

$10 \% \mathrm{DEL}$ (d) $10 \% \mathrm{EL}$ (e) $20 \% \mathrm{DEL}$ (f) $40 \% \mathrm{DEL}$ (g) $60 \% \mathrm{DEL}$.

A high-resolution transmission electron microscope (TEM, JEOL, JEM-2100F) was used to observe the microphase structure of LPUe and the images were shown in Figure S9. No apparent phase separation was observed in the control sample, 5\%DEL and 10\%DEL (Figure S9a, b, c), which benefited from the excellent compatibility between DEL and the polyurethane matrix. As the DEL amount increased, 
micro-phase separation occurred in 20\%DEL and enhanced in 40\%DEL (Figure S9e, f). However, when the substitution amount of lignin reached $60 \%$, obvious lignin aggregation was observed in 60\%DEL (Figure S9g). Compared with 10\%DEL, apparent lignin particles could be observed in 10\%EL (Figure S9d), confirming that partially depolymerization of EL could improve the interfacial compatibility between lignin and polyurethane matrix

\section{References}

[1] Xu, L.; Bai, L. G.; Yan, T. Z.; Wang, Y. Z.; Wang, J.; Liang, B. Application of Synchrotron Radiation Small and Wide Angle X-ray Scattering in the Research of Polymer Materials. Polym. Bull. 2010, (10), 1-26.

[2] Yu, X.; Chen, E. Q.; Zhu, C. S.; He, S. Q.; Liu, W. T. Study of lamellar morphology of poly( $\varepsilon$-caprolactone) based on SAXS/WAXS simultaneous measurement and one-dimensional correlation function analysis. Acta Polym. Sin. 2010, (09), 1136-1142.

[3] Chen, L.; Chen, H. P.; Lu, Q.; Song, Y.; Ding, X. J.; Wang, X. H.; Yang, H. P. Characterization of structure and pyrolysis behavior of lignin. CIESC J. 2014, 65 (09), 3626-3633.

[4] Kubo, S.; Kadla, J. F. Hydrogen bonding in lignin: a Fourier transform infrared model compound study. Biomacromolecules 2005, 6 (5), 2815-2821.

[5] Del Rio, J. C.; Gutierrez, A.; Rodriguez, I. M.; Ibarra, D.; Martinez, A. T. Composition of non-woody plant lignins and cinnamic acids by $\mathrm{Py}-\mathrm{GC} / \mathrm{MS}$, Py/TMAH and FTIR. J. Anal. Appl. Pyrolysis 2007, 79 (1-2), 39-46.

[6] Li, H.; Sun, J. T.; Wang, C.; Liu, S. L.; Yuan, D.; Zhou, X.; Tan, J.; Stubbs, P.; He, C. B. High modulus, strength, and toughness polyurethane elastomer based on unmodified lignin. ACS Sustainable Chem. Eng. 2017, 5 (9), 7942-7949.

[7] Argyropoulos, D. Quantitative phosphorus $-{ }^{31} \mathrm{P}$ NMR analysis of lignins, a new tool for the lignin chemist. J. Wood Chem. Technol. 1994,14 (1), 45-63. 